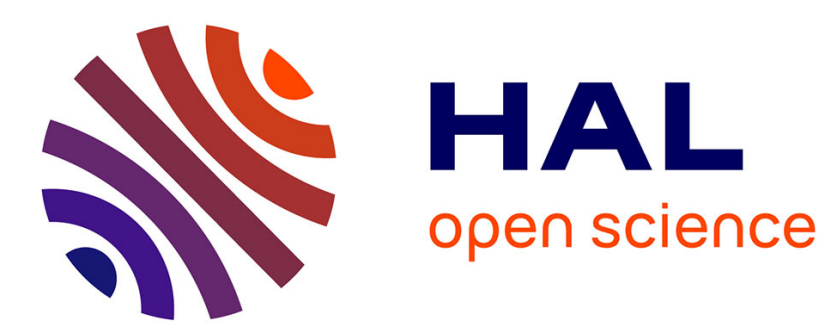

\title{
Reply to Comment on 'Issues in the understanding of negative ion extraction for fusion'
}

\author{
Jean-Pierre Boeuf, G. Fubiani, Laurent Garrigues
}

\section{To cite this version:}

Jean-Pierre Boeuf, G. Fubiani, Laurent Garrigues. Reply to Comment on 'Issues in the understanding of negative ion extraction for fusion'. Plasma Sources Science and Technology, 2017, 26 (5), pp.058002. 10.1088/1361-6595/aa68c9 . hal-02326702

\section{HAL Id: hal-02326702 \\ https://hal.science/hal-02326702}

Submitted on 23 Oct 2019

HAL is a multi-disciplinary open access archive for the deposit and dissemination of scientific research documents, whether they are published or not. The documents may come from teaching and research institutions in France or abroad, or from public or private research centers.
L'archive ouverte pluridisciplinaire HAL, est destinée au dépôt et à la diffusion de documents scientifiques de niveau recherche, publiés ou non, émanant des établissements d'enseignement et de recherche français ou étrangers, des laboratoires publics ou privés. 


\title{
Reply to the comment on "Issues in the understanding of negative ion extraction for fusion "
}

JP Boeuf, G Fubiani, L Garrigues

LAPLACE, Université de Toulouse, CNRS, INPT, UPS, Toulouse, France

Email : jpb@laplace.univ-tlse.fr

\begin{abstract}
In this reply we respond to the comments of Mochalskyy et al. on our paper "Issues in the understanding of negative ion extraction for fusion " where we pointed out some errors in previously published papers reporting results of Particle-In-Cell Monte Carlo Collisions (PIC MCC) of negative ion extraction. We stress again that 1 ) it is always better to solve properly a simplified problem than to present misleading simulation results albeit under conditions closer to the real problem and 2) good comparison of simulation to experimental results does not constitute validation of the simulation if accuracy of the simulation is doubtful unless thorough verification of the simulation has been carried out.
\end{abstract}

The authors of the comment [1] list specific and detailed points related to our criticism of their published work on the simulation of negative ion extraction. They claim that their simulations results are in agreement with experiments whereas we showed in our initial paper that their results and their conclusions are wrong because of misuse of the PIC MCC simulations. We do not respond separately to each point raised, but rather we give an overall response to the comment.

It seems that the purpose of our initial paper [2] was not understood by the authors of the comment. We summarize below, in the context of the comment, the main points of our initial paper [2]:

- PIC MCC simulations that do not satisfy the elementary constraints on the mesh size and time step can lead to erroneous results and hence misleading conclusions. This was shown in our first paper [2] in the context of negative ion extraction and was more systematically illustrated in our following papers [3] and [4]. This point is well known by the plasma simulation community and it is surprising that the authors of the comment and of the criticized papers (see [1] and references therein) used mesh sizes much larger than the Debye length, their argument being that the number of mesh points must be limited in order to carry out 3D simulations. Moreover the method of injection of the plasma particles in the simulation domain was not correct in these papers, as shown in [2] and [3], and led to non-physical results. Note that even if there is no error in a PIC code, its use with inappropriate mesh size, time step, or number of particles per cell leads to erroneous results (the mesh size was up to 5 times larger than the Debye length in some regions of the simulation domain and some simulations were performed with only a few particles per cell in the papers by the authors of the comment). Verification of the convergence of PIC results with these parameters is therefore essential [3], [4].

- We showed that inappropriate choice of mesh size in the PIC simulations can lead to erroneous conclusions. In the simulation results of the authors of the comment (see [1] and references therein), it appears that negative ions are not extracted from a quasineutral plasma behind a 
meniscus, but rather from the tips of the chamfered grid apertures where the electric field was sufficiently large to directly (i.e. without space charge neutralization) extract a large negative ion current density from the cesiated surface. We illustrated by using a 2D PIC model that negative ions can be extracted from a large part of the cesiated surface provided that the negative ion density in front of the surface is neutralized by the presence of positive ions. We assert that the conclusions drawn by the authors of the comments are wrong in this regard because of misuse of the PIC simulations (3D).

- Our initial paper also identified some important issues in the definition of the model of negative ion extraction: role of the boundary conditions, method of plasma injection etc... That is, in addition to questions of accuracy of the simulations or feasibility of modeling real conditions (3D simulations with real plasma densities, i.e. small mesh sizes), we showed that there were still issues in the definition of the model. These issues should be considered and addressed by the different groups involved in the simulation of negative ion extraction to improve the models.

- Finally we wish to stress that a simplified model of a real problem can be extremely useful to help understand the essential aspects of the problem. And, even though it may not be fully predictive, it can often provide essential information regarding the trends of the results when some parameters are changed. In the case of negative ion extraction, we know that $2 \mathrm{D}$ and $3 \mathrm{D}$ simulations with plasma densities lower that the real ones are tractable in terms of computation time, whereas this is not the case for 3D simulations with real values of the plasma densities because of the large number of grid points required (at least in explicit simulations). We believe that even if exact scaling laws will be difficult to define, simulations performed with lower plasma densities can provide extremely useful information on the qualitative and quantitative features of negative ion extraction (work is in progress to define approximate scaling laws). In any cases, it seems to us that accurate PIC calculations at lower densities are infinitely more useful than wrong calculations performed for the real plasma densities.

We conclude by quoting one sentence of the authors of the comment: "The chosen mesh size in the ONIX code is a compromise between the available computing time and accuracy." Our point is that accuracy should not be compromised when it is known that the lack of accuracy can lead to nonphysical results (which is the case in PIC simulations). Convergence tests are the only way to resolve questions concerning accuracy and its impact on the conclusions concerning the interplay of various physical phenomena. We have proposed in [4] some conditions and simulation results that can be used for future benchmarking of PIC MCC codes in the context of negative ion extraction.

\section{References}

[1] S Mochalskyy, T Minea, A Revel, I Montellano, D Wunderlich, U Fantz, Comment on "Issues in the understanding of negative ion extraction for fusion", Plasma Sources Sci. Technol. ... (2017)

[2] JP Boeuf, G Fubiani, L Garrigues, Plasma Sources Sci. Technol. 25045010 (2016)

[3] L Garrigues, G Fubiani, JP Boeuf, Nucl. Fusion 57014003 (2017)

[4] L Garrigues, G Fubiani, JP Boeuf, J. Appl. Phys. 120213303 (2016) 